\title{
Design and Development of False Ceiling Board Using Polyvinyl Acetate (PVAc) Composite Reinforced with False Banana Fibres and Filled with Sawdust
}

\author{
Yerdawu Zeleke $\mathbb{D}^{1}$ and Gideon K. Rotich $\mathbb{D D}^{1,2}$ \\ ${ }^{1}$ Textile Manufacturing, Ethiopian Institute of Textile and Fashion Technology, Bahir Dar University, Ethiopia \\ ${ }^{2}$ Clothing and Textiles, School of Engineering and Technology, South Eastern Kenya University, Kenya \\ Correspondence should be addressed to Gideon K. Rotich; rotichgideon@yahoo.com
}

Received 30 January 2021; Revised 13 March 2021; Accepted 29 March 2021; Published 19 April 2021

Academic Editor: Antonio Caggiano

Copyright (c) 2021 Yerdawu Zeleke and Gideon K. Rotich. This is an open access article distributed under the Creative Commons Attribution License, which permits unrestricted use, distribution, and reproduction in any medium, provided the original work is properly cited.

\begin{abstract}
This work deals with design and development of false ceiling board from polyvinyl-acetate (PVAc) composite reinforced with false banana fibres and filled with sawdust. The aim was to develop a light weight and good strength performance false ceiling board using raw materials that are fully biodegradable including sawdust, thus solving the problem of its disposal. The false banana fibres were characterized for its tensile strength, elongation, and moisture content since these parameters affect the composite properties. Hand lay-up method combined with compression molding followed by curing was utilised in the manufacture of the false ceiling composites. The optimum proportions of the raw materials were identified using central composite design software, and the results were $40 \%$ sawdust, $40 \%$ binder (PVAc), and $20 \%$ fibres. The mechanical properties of the developed composite board were evaluated in terms of its tensile strength, flexural strength, and compressive strength. In addition, the composite physical properties were also evaluated including its density and moisture absorption. The optimum results obtained were tensile strength of $12.54 \mathrm{~N} / \mathrm{mm}^{2}$, compressive strength of $7.03 \mathrm{~N} / \mathrm{mm}^{2}$, and flexural strength of $5.13 \mathrm{~N} / \mathrm{mm}^{2}$.
\end{abstract}

\section{Introduction}

The utilization of composites as load bearing structures has been increasing at a faster rate. One of the composite material advantage is its ability to be designed with desirable characteristics suiting the intended purpose [1]. Of late, coarse cellulosic fibers have received significant consideration as alternatives for synthetic fiber as composite reinforcements. This is because the plant fibers impart certain advantages to the composites for instance low density, high stiffness, low cost, renewability, biodegradability, eco-friendly, and high degree of flexibility throughout processing $[2,3]$. The properties of natural fiber greatly affect the performance of its reinforced composites. These properties include fiber fineness, fiber length, distribution, its arrangement, and fiber percentage in the composite plus the stacking orientation in the composite structure [4]. These natural fibers can be extracted from conventional sources as well as from nonconventional sources like agricul- tural by-products. The natural fibres can be a suitable substitute of synthetic fibres because they are available at a low cost and possess inherent environmentally friendly properties [5].

Natural fibres (NF) are preferable for their appropriate stiffness, mechanical properties, and high disposability [6]. Natural fibre-based composites are becoming important composite materials in automotive, packaging, building, and civil engineering fields, due to their light weight, high strength to weight ratio, and corrosion resistance among other advantages [7]. Among the natural fibres, false banana fibres (Ensete Fibers) are widely used natural fibres in the southern parts of Ethiopia. It is a lingo-cellulose fibre, obtained from the pseudostem of false banana plant (Musa sepientum) with relatively good mechanical properties. The properties of false banana fibre include low cost, low density, biodegradability, renewability, good mechanical properties, and nontoxicity [6]. According to Muller [8], false banana fibres have been used for the production of ropes and can be 
used as a reinforcing fiber in composite materials [9-13]. Banana fibers have also been used with other fibers to produce hybrid composites [14]. Manickam and coworkers studied the mechanical and water intake properties of banana-carbon hybrid fiber-reinforced polymer composites [15]. They found out that the hybrid composites had comparable properties with carbon fiber-reinforced composite but had higher water intake because of inclusion of banana fibers. The effect of alkaline treatment on banana fibers on the performance of banana fiber/epoxy composites has been studied $[16,17]$.

The composite bulk properties can be enhanced by in cooperating fillers during its manufacture. These fillers can be ballast, sand, $\mathrm{CaCO}_{3}$, and sawdust. This work is aimed at using sawdust as a filler which is one of the major industrial wastes resulting from wood exploitation and processing. These sawdust are being disposed in uncontrolled conditions leading to environmental pollution. They can be used to provide heat energy, but resulting pollutants such as ash and air pollutants emanated through the combustion gases, carbon monoxide (CO), volatile organic compounds (VOCs), nitrogen oxides (NOx), sulfur oxides (SOx), and particular emissions (PE) affect human respiratory system [18]. Currently, the disposal of waste to the environment has laid additional pressure to the already fragile environment due to pollution [19].

A number of researchers are working on different ways to dispose-off the variety of agricultural and industrial wastes to minimize their effect on the environment. According to Ataguba et al. reports [20], some of the waste products as sawdust can be recycled into new products that are more environmentally friendly. Natural fiber-reinforced composite boards have been manufactured using sawdust and natural fibres, in order to replace the conventional materials like wood, metals, and asbestos [21, 22]. Yakubu produced a composite ceiling board from agro-waste used in houses to reduce sound and heat while giving additional aesthetics [23].

Apart from reinforcing fibers and fillers, the matrix part also affects the performance of composite material. The matrix used can be thermoset or thermoplastic, and for this work, polyvinyl acetate (PVAc) was used. Shedge and Patel reports that polyvinyl acetate resin is a selective binder, due to its well-known adhesion property with cellulosic materials because of the presence of polar acetyl groups [24]. The acetate of the binder can form physical bond with cellulosic material, and the best results are obtained with resin forming a sheath around each individual fibre.

The main aim of this study was to develop a false ceiling board using polyvinyl acetate composite filled with sawdust and reinforced with false banana fibres. The raw materials are eco-friendly, biodegradable, and helps to increase the potential use of the waste sawdust rather than disposing it to the environment. The mechanical properties (tensile strength, flexural strength, and compressive strength) and physical properties (moisture absorption and density) of the manufactured composite material were evaluated and reported.

\section{Materials and Experiments}

2.1. Materials. In this study, sawdust having a particle size of $1.8 \mathrm{~mm}$, evaluated using a sieve analyzer, was used as fillers,
TABLE 1: Physical properties of false banana fibres compared with other natural fibres $[4,25]$.

\begin{tabular}{lccc}
\hline Fibre & $\begin{array}{c}\text { Tensile strength } \\
(\mathrm{MPa})\end{array}$ & $\begin{array}{c}\text { Elongation at } \\
\text { break (\%) }\end{array}$ & $\begin{array}{c}\text { Moisture } \\
\text { content }(\%)\end{array}$ \\
\hline False & 454.15 & 1.5 & 10 \\
banana & 453 & 1.8 & 12 \\
Jute & 465 & 2.2 & 13.75 \\
Hemp & 560 & 3.0 & 12 \\
Flax & & & \\
\hline
\end{tabular}

and false banana fibres were used as reinforcing fibers. The fibres were locally sourced in Ethiopia, and its characterized properties compared with other conventional natural fibres are presented in Table 1.

The physical properties of false banana fibre, such as tensile strength, elongation at break, and moisture content, are moderate compared to other natural fibres as shown in Table 1. After characterization, the composite was developed according to constituent ratios suggested by central composite design software. The steps used, in order to develop the product, included preparation of the raw material (sawdust, resin, and fibres) followed by mixing the resin with the sawdust plus the fibres until a homogeneous mixture was achieved. Layer-by-layer stacking was done before it was cold pressed pneumatically at a pressure of $80 \mathrm{~kg} / \mathrm{m}^{2}$ followed by drying and curing at room temperature.

\subsection{Experimental Tests}

2.2.1. Tensile Strength. The tensile strength of the manufactured sample, size of $(5 \times 15 \times 1) \mathrm{cm}$, was tested using universal tensile testing machine as per the ASTM D1037 test standard [26]. The composite tensile strength was calculated using Equation (1) [27]:

$$
\delta t=\frac{W t}{b t}
$$

where $\delta t$ is the tensile strength $\left(\mathrm{N} / \mathrm{mm}^{2}\right), W_{t}$ is the failure tensile load $(\mathrm{N}), b$ is the width of the specimen $(\mathrm{mm})$, and $t$ is the thickness of the specimen (mm).

2.2.2. Compressive Strength. Compressive strength test was carried out using universal tensile testing machine as per the ASTM D1037 test standard [26], and the specimen size was a cube of $(2.5 \times 2.5 \times 2.5) \mathrm{cm}$. The compressive strength was calculated using Equation (2).

$$
T_{c}=\frac{W c}{b t}
$$

where $T_{c}$ is the compressive strength $\left(\mathrm{N} / \mathrm{mm}^{2}\right), W_{c}(\mathrm{~N})$ is the failure load, and $b$ and $t$ are the width and the thickness of the sample $(\mathrm{mm})$, respectively.

2.2.3. Flexural Strength. Flexural strength test was carried out using universal tensile testing machine as per the ASTM D790 test standard [28]. The specimen size was $(5 \times 15 \times 1)$ 
TABLe 2: Mechanical properties of the composite with different constituents' ratios.

\begin{tabular}{|c|c|c|c|c|c|c|}
\hline $\begin{array}{l}\text { Run } \\
\text { number }\end{array}$ & $\begin{array}{l}\text { Sawdust } \\
(\%)\end{array}$ & $\begin{array}{c}\text { Resin } \\
(\%)\end{array}$ & $\begin{array}{l}\text { Fibre } \\
(\%)\end{array}$ & $\begin{array}{l}\text { Tensile strength in } \\
\qquad \mathrm{N} / \mathrm{mm}^{2}\end{array}$ & $\begin{array}{l}\text { Compressive strength in } \\
\mathrm{N} / \mathrm{mm}^{2}\end{array}$ & $\begin{array}{l}\text { Flexural strength in } \\
\mathrm{N} / \mathrm{mm}^{2}\end{array}$ \\
\hline 1 & 41.20 & 41.2 & 17.6 & 7.98 & 4.82 & 4.45 \\
\hline 2 & 45.5 & 45.5 & 9 & 5.63 & 3.56 & 3.87 \\
\hline 3 & 41.5 & 41.5 & 17 & 8.12 & 4.42 & 4.21 \\
\hline 4 & 41.5 & 41.5 & 17 & 9.23 & 4.63 & 4.19 \\
\hline 5 & 37.5 & 37.5 & 25 & 10.19 & 5.98 & 4.47 \\
\hline 6 & 44.5 & 33.5 & 22 & 5.93 & 4.15 & 4.33 \\
\hline 7 & 44.5 & 44.5 & 11 & 11.40 & 6.26 & 4.12 \\
\hline 8 & 41.5 & 41.5 & 17 & 9.0 & 4.86 & 4.46 \\
\hline 9 & 42.80 & 42.8 & 14.4 & 4.13 & 2.36 & 3.63 \\
\hline 10 & 40 & 40 & 20 & 12.54 & 7.03 & 5.13 \\
\hline 11 & 45.5 & 34.5 & 20 & 3.96 & 1.52 & 2.89 \\
\hline 12 & 39.5 & 45.5 & 15 & 12.35 & 6.95 & 4.16 \\
\hline 13 & 41.5 & 41.5 & 17 & 9.13 & 4.45 & 4.43 \\
\hline 14 & 37.5 & 37.5 & 25 & 6.20 & 3.34 & 3.72 \\
\hline 15 & 34.5 & 46.5 & 19 & 7.45 & 3.52 & 4.58 \\
\hline 16 & 37.5 & 50 & 12.5 & 9.89 & 5.43 & 4.32 \\
\hline 17 & 41.5 & 41.5 & 17 & 9.14 & 4.68 & 4.37 \\
\hline 18 & 46.5 & 37.5 & 16 & 11.02 & 5.66 & 4.91 \\
\hline 19 & 50 & 37.5 & 12.5 & 7.01 & 2.96 & 3.57 \\
\hline 20 & 34 & 44 & 22 & 11.25 & 5.95 & 4.68 \\
\hline
\end{tabular}

$\mathrm{cm}$, and the composite flexural strength was calculated using Equation (3) [29].

$$
\sigma=S \times F=\frac{3 P S}{2 b t 2},
$$

where $\sigma$ is the flexural strength $\left(\mathrm{N} / \mathrm{m}^{2}\right), P$ is the maximum test load $(\mathrm{N}), S$ is the dimension between load points $(\mathrm{mm})$, $b$ is the sample width $(\mathrm{mm})$, and $t$ is the sample thickness (mm).

2.2.4. Water Absorption. Water absorption test was carried out by immersing the composite sample in water for 2 hours and 24 hours at room temperature as per ASTM D570 test standard [30]. The water absorption of the composite material was determined using Equation (4).

$$
\% W=\frac{\left(W_{t}-W_{o}\right)}{W_{o}} \times 100
$$

where $W_{t}$ is the weight of the composite after immersion in water and $W_{o}$ is the weight of the dried sample.

2.2.5. Density. Density of the manufactured composite was obtained both theoretically (weight ratio method) and areal density (by using Archimedes principle) which was also used to evaluate the void fraction \% of the composite material.

\section{Result and Discussion}

3.1. Optimum Proportions. The test results of the manufactured samples, developed according to the proportions sug- gested by central composite design software, are presented in Table 2. The optimal values according to the response surface method were $40 \%$ sawdust, $40 \%$ resin, and $20 \%$ fibres, as per the experimental results. The optimal mechanical properties obtained were tensile strength of $12.54 \mathrm{~N} / \mathrm{mm}^{2}$, compressive strength of $7.03 \mathrm{~N} / \mathrm{mm}^{2}$, and flexural strength of $5.13 \mathrm{~N} / \mathrm{mm}^{2}$.

3.2. Tensile Strength. Figure 1 shows the effect of single factors on composite tensile strength. It can be seen that when the proportions of the constituents increased, the strength of the composite increased. As the proportion of the sawdust increased, the tensile strength increased but only slightly. This could be because sawdust was used as a filler to contribute the bulk properties but not directly affecting the strength properties [31]. The low increase in tensile modulus could be ascribed to two probable explanations, one being a poor dispersion of the sawdust particles throughout the matrix, and the other is the moisture pick-up in the sawdust [32]. The other reason could be its size of $1.8 \mathrm{~mm}$ was too short to carry any significant load.

As for the increase in resin ratio, there was a great increase in tensile strength probably due the fact that when the resin proportion increased, efficient wetting of the constituent parts was realised. This in turn increased the gluing power of the resin which translated into increased tensile strength. Under loading situation, the resin plays the main part of transmitting the forces across the composites. For composite to perform well under shear forces, the resin phase must not only show acceptable mechanical properties but must also bond well with the reinforcing fibre. The tensile 

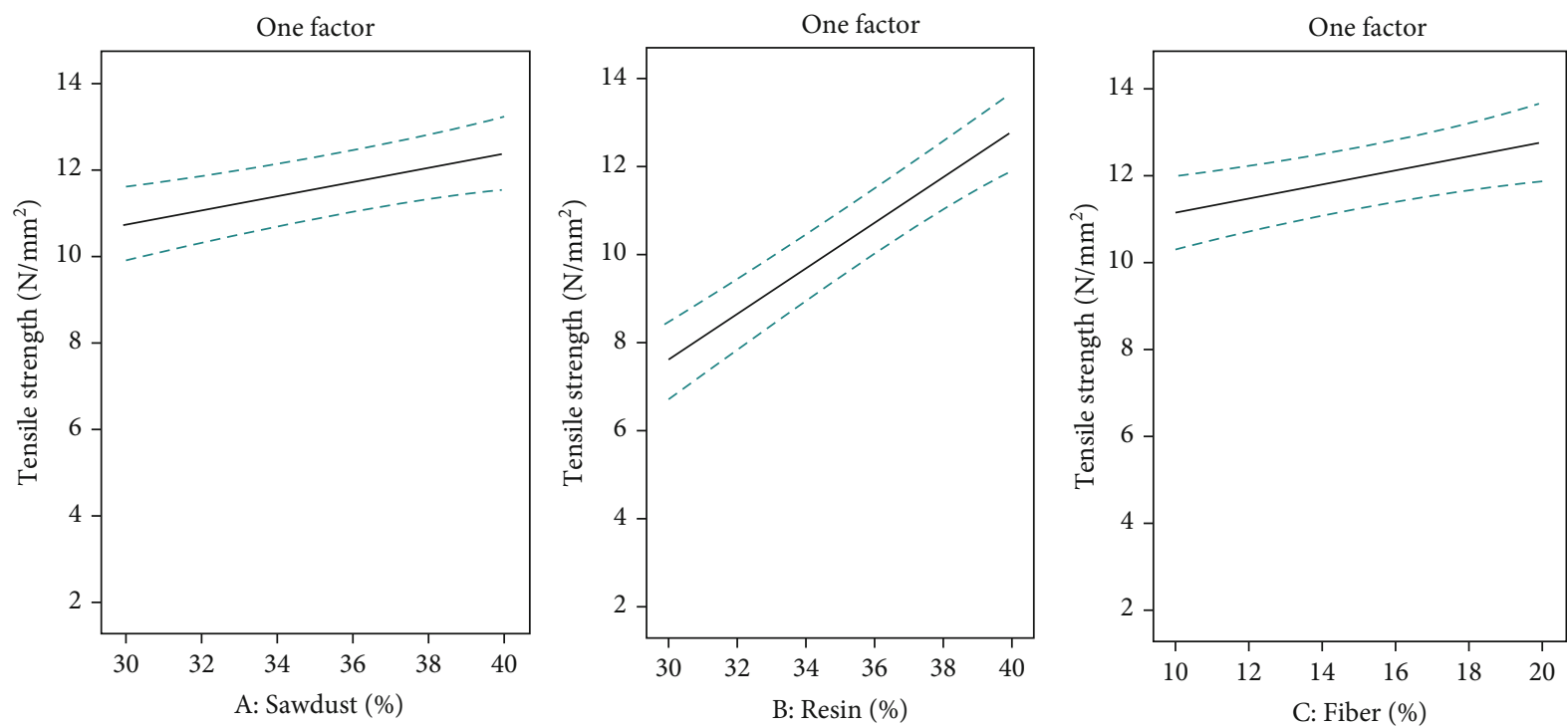

FIgURE 1: The effect of factors on tensile strength.
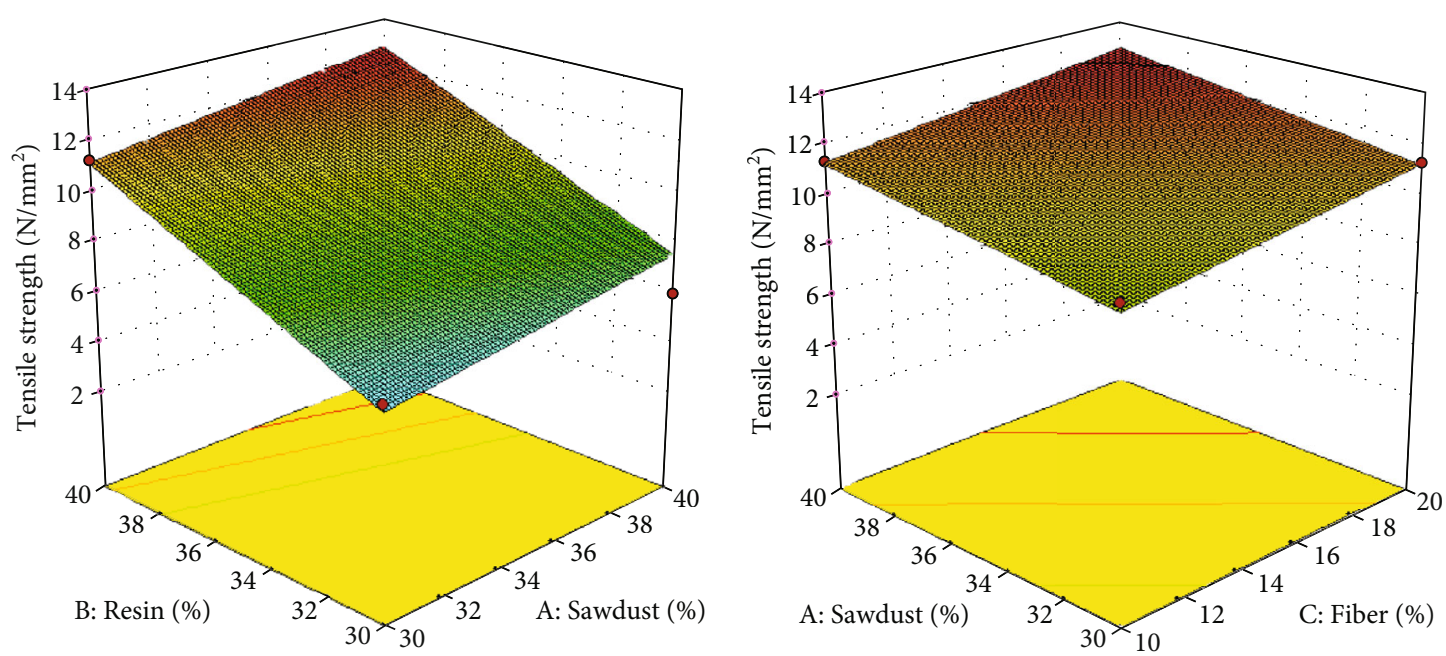

FIGURE 2: Effect of fibres, sawdust, and resin on tensile strength of the composite.

load for a composite is reliant on reaction of a composite to tensile loads and also reliant on the strength properties of the reinforcing fibres, since they are strong in relation to the resin system on its own. The increase in fibre proportion also resulted in increase in tensile strength. The reason was that more fibres were available to carry the load [33]. The moderately lower values for the composites manufactured are attributable to the nonuniform stress transmission because of the random orientation of the fibres in the matrix.

Figure 2 shows the combined effect of factors on the tensile strength of the composite. It can be seen that the combined effect on tensile strength of resin and sawdust was higher than the combined effect of sawdust and fibres. The effects of factors (sawdust, resin, and fibre) were positive over tensile strength of the composite material; when the factors increased up to optimum level, the tensile strength also increased linearly. But the factor values above optimum per- centage caused the tensile strength of the composite material to reduce. The tensile strength reduced above optimum values due to the poor interface bonding between the matrix, fillers, and fibres, and also, there was incomplete wetting of the fibre by the resin at a higher fibre proportion [33].

ANOVA analysis was performed to check the influence of the input variables on the tensile strength of the manufactured composite. ANOVA Table 3 shows the factors (sawdust, resin, and fibre) had significant influence on the tensile strength with $P$ values of less than 0.05 . The proposed model was also significant with a $P$ value of $<0.0001$.

Equation (5) shows a developed model equation that can be used to predict the composite tensile strength from the constituent proportions.

$$
\text { Tensile strength }=-18.45558+0.16715 . A+0.52604 . B
$$$$
+0.16342 . C
$$ 
TABle 3: ANOVA table for composite tensile strength.

\begin{tabular}{lcccccc}
\hline Source & Sum of squares & D.F & Mean square & $F$ value & $P$ value & Significant \\
\hline Model & 113.13 & 3 & 37.71 & 59.35 & $<0.0001$ & 0.0013 \\
A-sawdust & 9.54 & 1 & 9.54 & 94.48 & 148.68 & 0.0001 \\
B-resin & 94.48 & 1 & 9.12 & 14.35 & 0.0016 & 0.1637 \\
C-fibre & 9.12 & 1 & 0.78 & 2.48 & Insignificant \\
Lack of fit & 8.59 & 11 & &
\end{tabular}
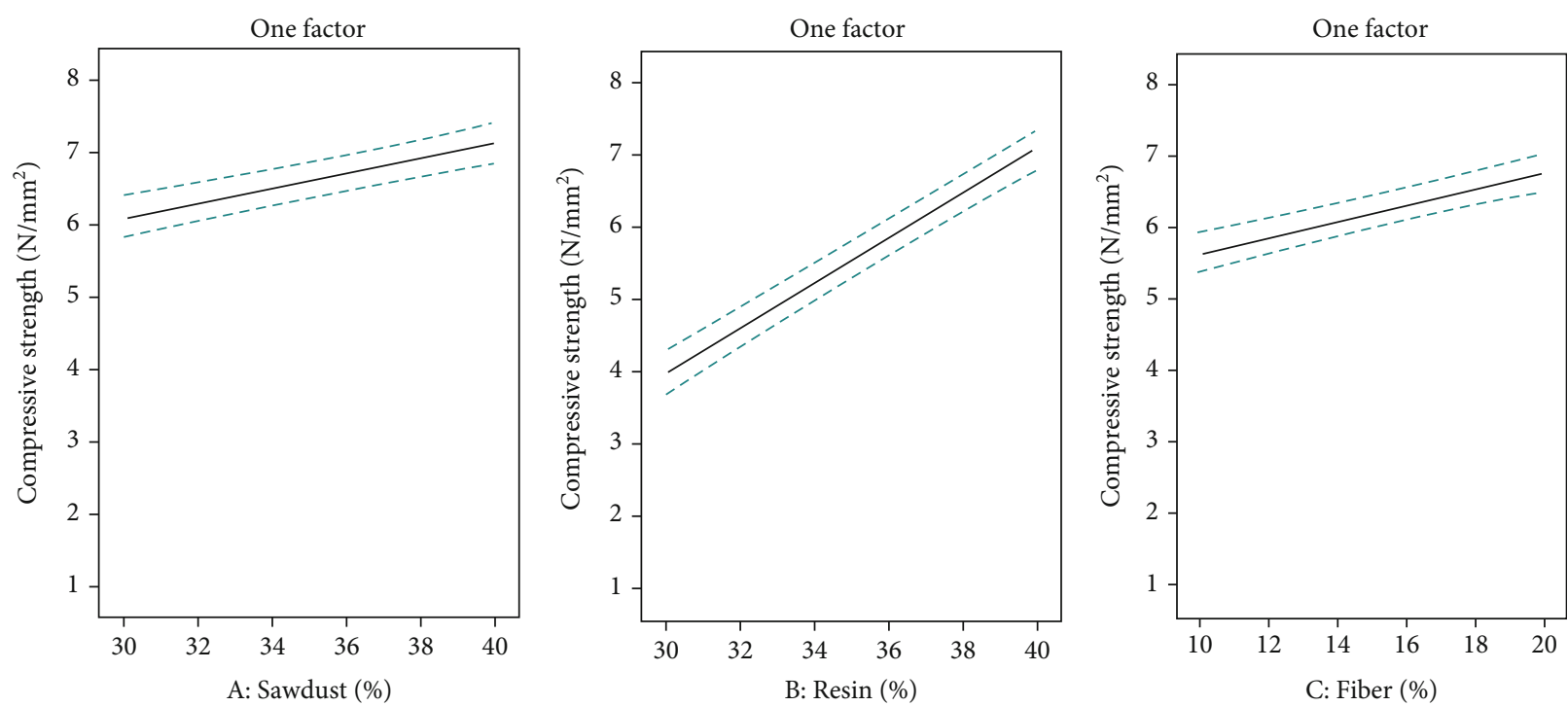

Figure 3: The effect of factors on compressive strength.

where $A$ is the sawdust proportion, $B$ is the resin proportion, and $C$ is the fibre proportion.

3.3. Compression Strength. Figure 3 shows the effect of single factors on the composite compression strength. It can be seen that as the ratio of the composite constituents increased, the compression strength of the composite increased. As the ratio of the sawdust increased, the compression strength increases but only slightly. This could be due to the fact that sawdust was used as a filler to increase the bulk properties but not directly affecting the strength properties. As for the increase in resin, there was a higher increase in compression strength perhaps due the fact that as the resin ratio increased, complete wetting of the constituent parts was amplified. This in turn increased the bonding power of the resin translating to increased compression strength. The increase in fibre proportion also resulted in increase in compression strength. The reason could be that more compressive load was carried by more fibres, hence higher strength. The same conclusion has also been discussed [34].

The combined percentage increase of sawdust, resin, and fibre significantly affected the compressive strength as shown in Figure 4. However, it increased only up to optimum level, but above optimum values, the composite compressive strength decreased. This may be because the distribution of filler on the composite material decreased while the amount of void fraction inside the composite material increased at low matrix proportion.

ANOVA analysis was performed to check the influence of the input variables on the composite compressive strength. ANOVA Table 4 shows the factors (sawdust, resin, and fibre) had significant influence on the compressive strength of the composite with $P$ values of less than 0.05 . The proposed model was also significant with a $P$ value of $<0.0001$.

Equation (6) shows a developed model equation that can be used to predict the composite compressive strength from the constituents ratios.

Compressive strength $=-11.52384+0.10133 . A+0.30742 . B$

$$
+0.11027 . C \text {, }
$$

where $A$ is the sawdust proportion, $B$ is the resin proportion, and $C$ is the fibre proportion.

3.4. Flexural Strength. The 3-point flexural test is commonly used to evaluate the physical property of composite resin reinforced materials especially under bending forces. From Figure 5, the flexural strength increased gradually with the increase in sawdust, resin, and fibre proportions. An increase in fibre content from 10 to $20 \%$ on weight increased the flexural strength by about $25 \%$. This could be due to more fibres 

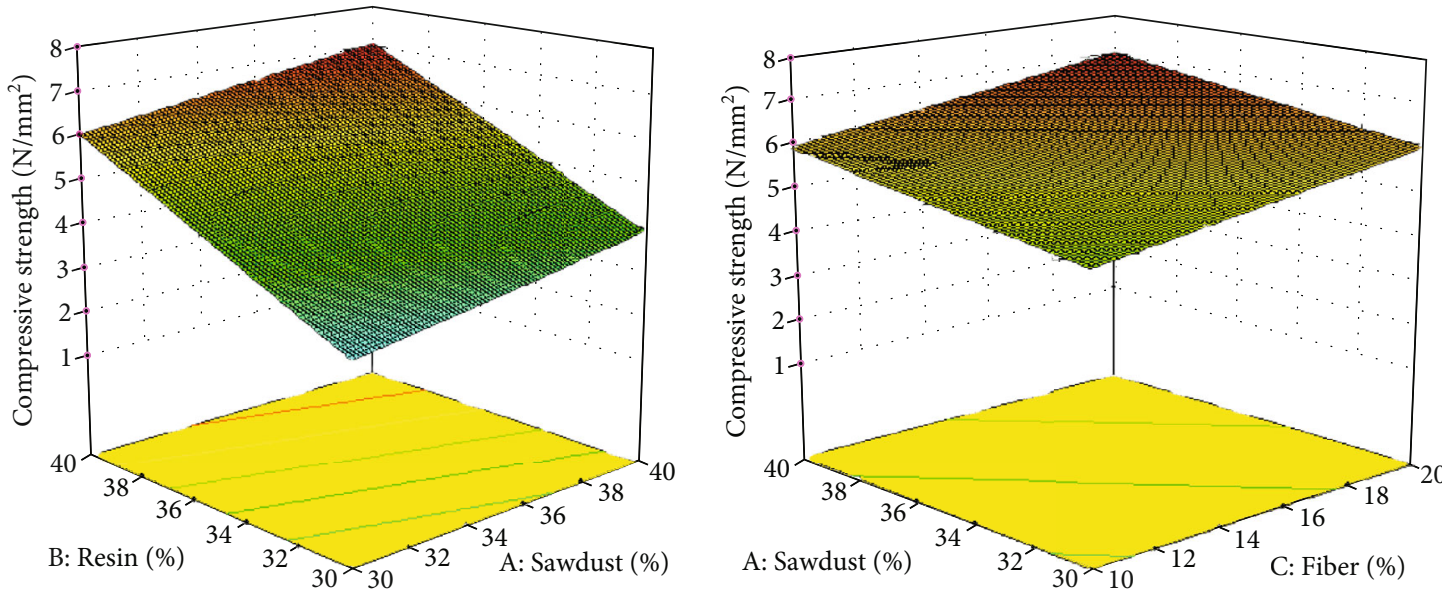

Figure 4: Effect of fibres, sawdust, and resin on compressive strength of the composite.

TABLE 4: ANOVA table for composite compressive strength.

\begin{tabular}{lcccccc}
\hline Source & Sum of squares & D.F & Mean square & $F$ value & $P$ value & Significant \\
\hline Model & 39.9 & 3 & 13.31 & 178.37 & $<0.0001$ & 0.0001 \\
A-sawdust & 3.51 & 1 & 3.51 & 32.27 & 432.47 & $<0.0001$ \\
B-resin & 32.27 & 1 & 4.15 & 55.65 & 0.0001 & 0.1331 \\
C-fiber & 4.15 & 1 & 0.093 & 2.80 & Insignificant \\
Lack of fit & 1.03 & 11 & & &
\end{tabular}
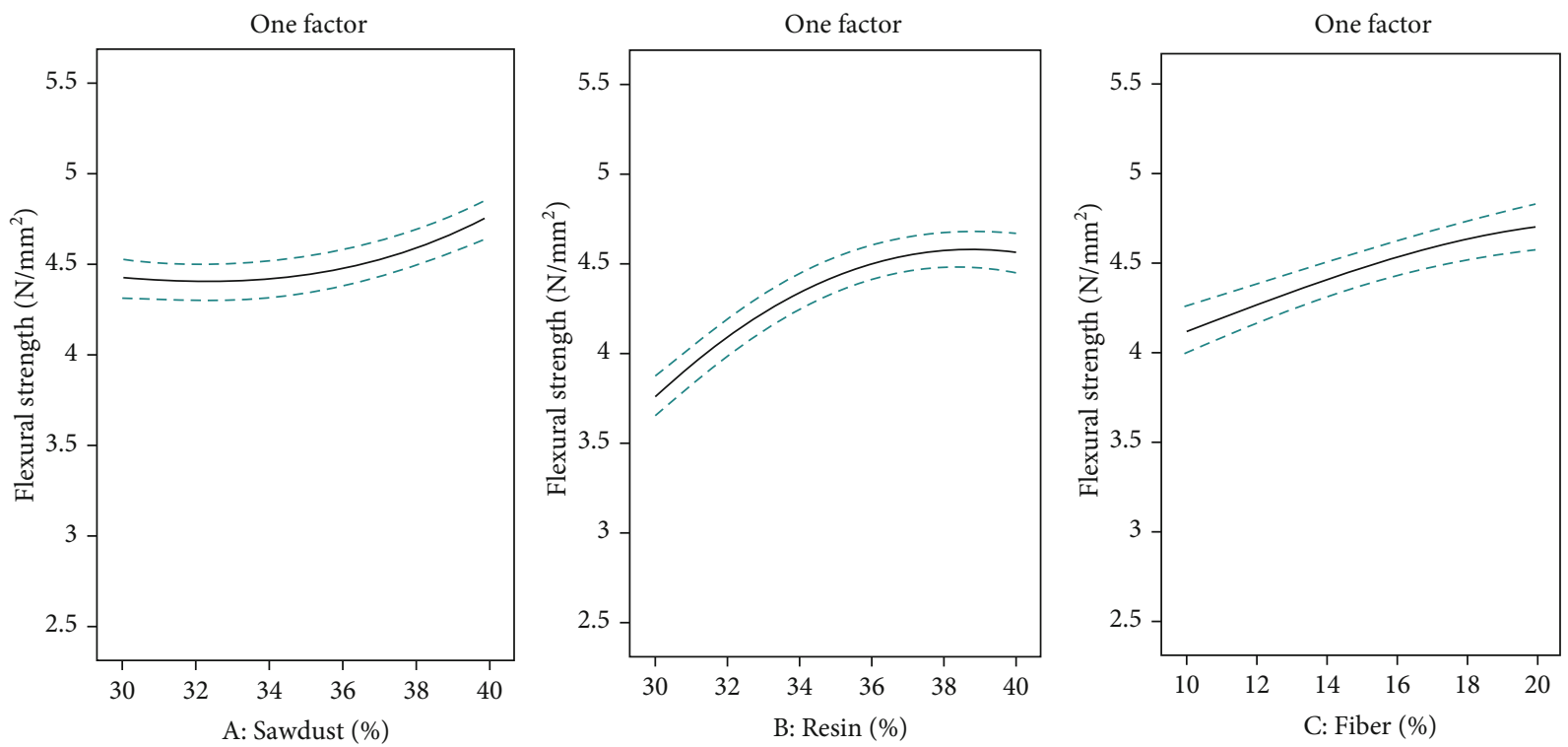

Figure 5: The effect of factors on flexural strength.

being present on a given composite cross-section to carry the load at a higher fibre weight \% [33]. However, further increase in fibre weight content above this value resulted in the lowering of the flexural strength. Similarly, an increase in resin proportion increased the flexural strength until an optimum value because with the increased interfacial interaction between the fibres and the matrices, the natural fibrereinforced composites become stronger [2]. Above this value, the flexural strength started to reduce probably due to strength becomes resin dependent rather than fibre 

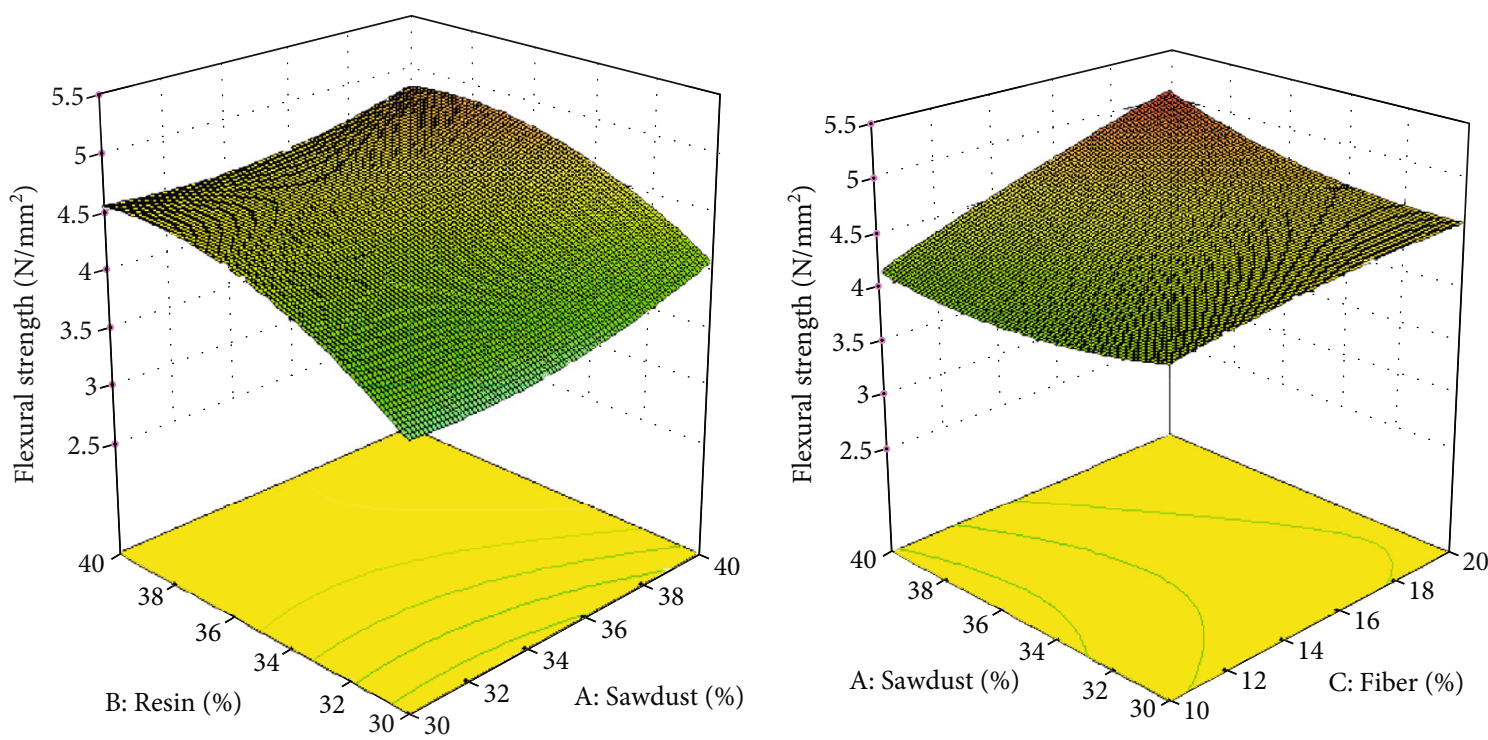

Figure 6: Effect of fibres, sawdust, and resin on flexural strength of the composite.

TABLE 5: ANOVA table for composite flexural strength.

\begin{tabular}{|c|c|c|c|c|c|c|}
\hline Source & Sum of squares & D.F & Mean square & $F$ value & $P$ value & \\
\hline Model & 4.72 & 9 & 0.52 & 45.27 & $<0.0001$ & Significant \\
\hline A-sawdust & 0.13 & 1 & 0.13 & 11.61 & 0.0001 & \\
\hline B-resin & 1.93 & 1 & 1.93 & 166.81 & $<0.0001$ & \\
\hline C-fiber & 0.76 & 1 & 0.76 & 65.94 & 0.0001 & \\
\hline $\mathrm{AC}$ & 0.22 & 1 & 0.22 & 18.81 & 0.0015 & \\
\hline $\mathrm{A}^{2}$ & 0.33 & 1 & 0.33 & 28.12 & 0.003 & \\
\hline $\mathrm{B}^{2}$ & 1.14 & 1 & 1.14 & 98.30 & 0.0001 & \\
\hline Lack of fit & 0.042 & 15 & 0.0083 & 0.56 & 0.7282 & Insignificant \\
\hline
\end{tabular}

dependent. The increase in sawdust proportion did not have a significant effect on the flexural strength.

Figure 6 presents the combine effect of factors on flexural strength of the manufactured composite samples. It shows that the input factors had a positive effect on flexural strength. As seen, resin proportion had the highest effect on the flexural strength of the composite. This is probably due to the fact that at a higher resin proportion, high gluing effect was achieved and more load will be transferred to the reinforcing fibres. But after optimum level, the flexural strength decreased. Flexural strength designates stiffness as well as the degree of deformation of a material when it is subjected to the flexural stress and offers ductility measure of a material. The ductile materials show lower flexural modulus as it experiences a significant deformation before failure happens. While the brittle materials possess a high value of flexural modulus as it fracture without undergoing a large deformation [35].

ANOVA analysis was performed to check the influence of the input variables on the composite flexural strength. ANOVA Table 5 shows the factors (sawdust, resin, and fibre) had significant influence on the composite flexural strength with $P$ values of less than 0.05 . The proposed model was also significant with a $P$ value of $<0.0001$.

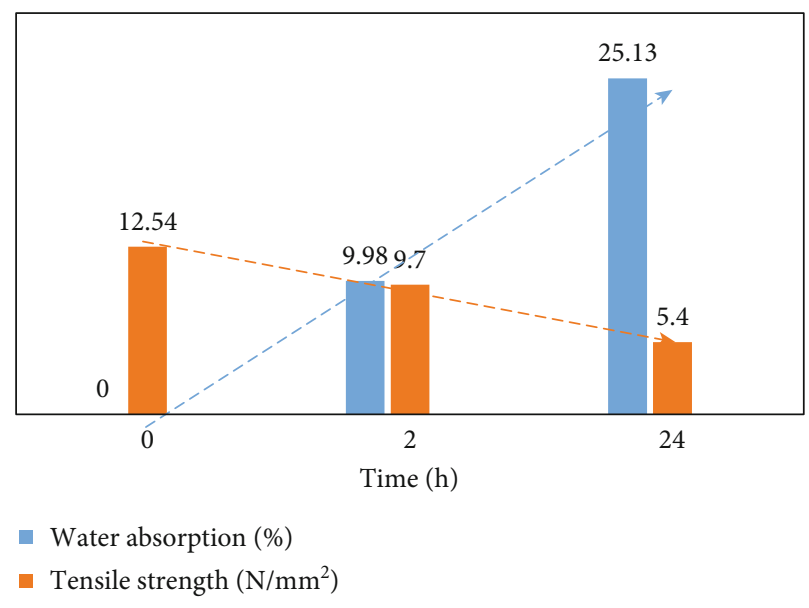

FIgURE 7: Water absorption test for 2 hours and 24 hours, respectively

Equation (7) shows a developed model equation that can be used to predict the composite flexural strength from the component proportions. 
TABLE 6: Density and void fraction of the composite material with different proportions.

\begin{tabular}{lcccccc}
\hline No. & Sawdust $(\%)$ & Resin $(\%)$ & Fibre $(\%)$ & Theoretical density $\left(\mathrm{g} / \mathrm{cm}^{3}\right)$ & Actual density $\left(\mathrm{g} / \mathrm{cm}^{3}\right)$ & Void fraction $(\%)$ \\
\hline 1 & 45.5 & 45.5 & 9 & 0.88 & 0.87 & 0.84 \\
2 & 44.5 & 33.5 & 22 & 0.86 & 0.88 & 2.33 \\
3 & 40 & 40 & 20 & 0.89 & 0.90 & 1.12 \\
4 & 34 & 44 & 22 & 0.91 & 0.85 & 1.10 \\
5 & 50 & 37.5 & 12.5 & 0.87 & 0.93 & 1.06 \\
6 & 37.5 & 50 & 12.5 & 0.94 & & 2.29 \\
\hline
\end{tabular}
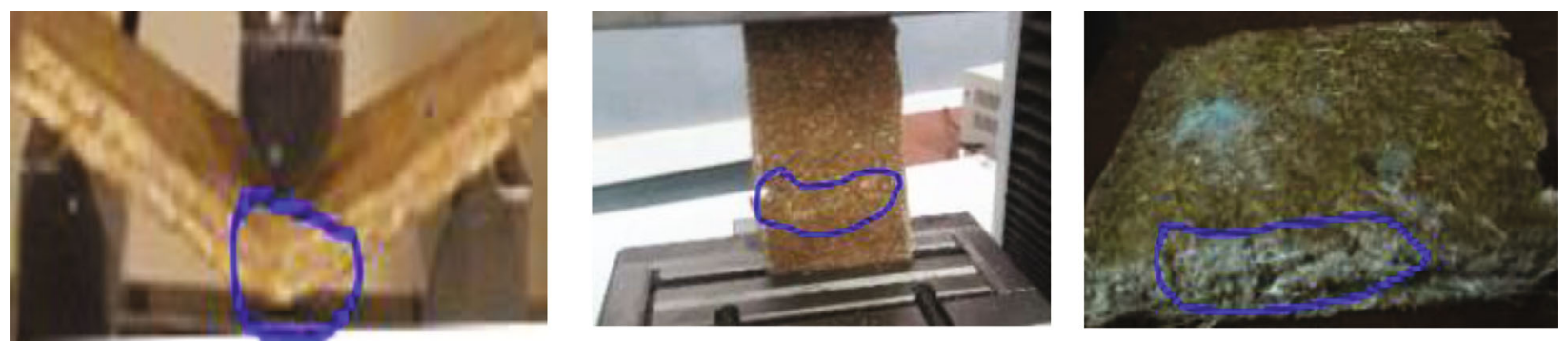

Figure 8: Damage morphology.

Flexural strength $=-3.51626-0.44751 . A+0.87560 . B$

$-0.21113 . C-0.0015 . A B+0.0066 . A C$

$+0.0026 . B C+0.006012 . A^{2}$

$-0.011241 . B^{2}-0.00211952 . C^{2}$,

where $A$ is the sawdust proportion, $B$ is the resin proportion, and $C$ is the fibre proportion.

3.5. Water Absorption. Evaluation of water absorption properties of natural fibre-reinforced polymer composites is very crucial since the hydrophilic groups on the surface are susceptible to moisture and water. The water absorption rest on diverse parameters such as fibre and sawdust wettability with the polymer matrix, interfacial adhesion, fabrication method, sawdust shape, size, and content voids content, temperature, and chemical structure of the sawdust. The water loving phenomena unfavourably affect the mechanical properties of natural fibre reinforced polymer composites and accelerate the microbial deterioration. The consequence of moisture absorption by the natural fibre-reinforced composite time and again turn out to be a disturbing indication in most applications. Essentially, this absorption totally destroys the bonding force between the fibre and matrix in a massive way. Consequently, it lowers the strength of the composite in due time depending on the immersion time or nature. It also result in poor stress transfer and ultimately to specimen fracture in the long run [36, 37]. The composite begins to swell when exposed to moisture giving rise to local strain in polymer matrix that causes microcracks, subsequently, decreasing the mechanical properties of composites [38, 39].

The results of water absorption test of composite sample manufactured with optimum percentage of the constituents (sawdust 40\%, resin 40\%, and fibre 20\%) are shown in Figure 7 after 2-hour and 24-hour immersion in water. As seen, as immersion time increased, the amount of water absorbed in the composite also increased which follows Fick's diffusion law [39]. This could be because the raw materials used for the composite manufacture were inherently hydrophilic due to the presence of hydroxyl groups on their surfaces. This shows that the composite developed should not be used for applications that are exposed to water. Figure 7 also shows the tensile strength of the composite reduced as the water absorbed increased. This is probably because the absorption completely terminates the bonding force between the fibre and matrix to a greater extent [39].

3.6. Density. The density of the composite material and its void fraction in percent are shown in Table 6.

From Table 6, the theoretical and actual density of the manufactured composite can be seen for different proportions of sawdust, resin, and fibres. The difference between the two densities shows the void fraction of the composite material which is a subject to the method of manufacture. At a lower proportion of resin, the void fraction was high probably due to the air voids between the fibres and sawdust which were reduced at a higher proportion since the resin filled these air voids.

3.7. Damage Morphology. Figure 8 shows the damage morphology exhibited by the composite during flexural, tension, and compression loading, respectively. This shows how the forces will be distributed and propagated during composite use. The damage morphology include matrix crack and fiber pull out when the composite was subjected to tensional forces while it experienced delamination and matrix crack when it was subjected to flexural and compressional forces. 


\section{Conclusion}

According to the obtained results, the developed composite from false banana fibres, filled with sawdust and polyvinylacetate, can be used to produce eco-friendly false ceiling board composite. The optimum proportion of the raw material was determined using design of expert (central composite design) software, and the best proportion was $40 \%$ sawdust, $40 \%$ resin, and $20 \%$ fibre based on the optimum composite properties. The mechanical properties of the manufactured composite at optimum level of constituent were tensile strength of $12.54 \mathrm{~N} / \mathrm{mm}^{2}$, flexural strength of $5.13 \mathrm{~N} / \mathrm{mm}^{2}$, and compressive strength of $7.03 \mathrm{~N} / \mathrm{mm}^{2}$. In addition, the composite water absorption properties were $9.88 \%$ and $25.13 \%$ after 2 hours and 24 hours, respectively, while the density of the composite material was between 0.87 and $0.93 \mathrm{~g} / \mathrm{cm}^{3}$. Therefore, the mechanical and physical properties of the developed false ceiling board composite showed good performance in terms of the evaluated properties. This study also indicates sawdust waste can be used to manufacture useful composite materials, such as false ceiling boards.

\section{Data Availability}

Sufficient data have been included in the manuscript. Additional data can be kindly requested from the authors.

\section{Conflicts of Interest}

There is no conflict of interest to declare.

\section{Acknowledgments}

The research was made possible by the support of the postgraduate office of Ethiopian Institute of Textile and Fashion Technology, Bahir Dar University, Ethiopia.

\section{References}

[1] C. C. Ihueze, C. E. Okafor, and C. I. Okoye, "Natural fiber composite design and characterization for limit stress prediction in multiaxial stress state," Journal of King Saud UniversityEngineering Sciences, vol. 27, no. 2, pp. 193-206, 2015.

[2] M. Syduzzaman, M. A. al Faruque, K. Bilisik, and M. Naebe, "Plant-based natural fibre reinforced composites: a review on fabrication, properties and applications," Coatings (Basel), vol. 10, no. 10, p. 973, 2020.

[3] F. Ko, L. Wan, and A. Bunsell, Handbook of Properties of Textile and Technical Fibres, Woodhead Publishing, 2018.

[4] U. Qasim, M. Ali, T. Ali, R. Iqbal, and F. Jamil, "Biomass derived fibers as a substitute to synthetic fibers in polymer composites," ChemBioEng Reviews, vol. 7, no. 6, pp. 193-215, 2020.

[5] M. P. M. Dicker, P. F. Duckworth, A. B. Baker, G. Francois, M. K. Hazzard, and P. M. Weaver, "Green composites: a review of material attributes and complementary applications," Composites Part A: Applied Science and Manufacturing, vol. 56, pp. 280-289, 2014.

[6] A. G. Temesgen and O. Sahu, "Process ability enhancement of false banana fibre for rural development," Cellulose, vol. 67, no. 67.89 , p. $67.63,2014$.
[7] P. V. Domke and V. D. Mude, "Natural fiber reinforced building materials," IOSR Journal of Mechanical and Civil Engineering, vol. 12, pp. 104-107, 2015.

[8] M. Müller, P. Valášek, and A. Ruggiero, "Strength characteristics of untreated short-fibre composites from the plant ensete ventricosum," BioResources, vol. 12, no. 1, pp. 255-269, 2017.

[9] J. Santhosh, "Study of properties of banana fiber reinforced composites," International Journal of Research in Engineering and Technology, vol. 3, no. 11, pp. 144-150, 2014.

[10] A. G. Adeniyi, J. O. Ighalo, and D. V. Onifade, "Banana and plantain fiber-reinforced polymer composites," Journal of Polymer Engineering, vol. 39, no. 7, pp. 597-611, 2019.

[11] M. Ramesh, T. S. A. Atreya, U. S. Aswin, H. Eashwar, and C. Deepa, "Processing and mechanical property evaluation of banana fiber reinforced polymer composites," Procedia Engineering, vol. 97, pp. 563-572, 2014.

[12] N. Amir, K. A. Z. Abidin, and F. B. M. Shiri, "Effects of fibre configuration on mechanical properties of banana fibre/PP/MAPP natural fibre reinforced polymer composite," Procedia engineering, vol. 184, pp. 573-580, 2017.

[13] E. M. Cadena Ch, J. M. Vélez R, J. F. Santa, and G. Viviana Otálvaro, "Natural fibers from plantain pseudostem (Musa paradisiaca) for use in fiber-reinforced composites," Journal of Natural Fibers, vol. 14, no. 5, pp. 678-690, 2017.

[14] R. Bhoopathi, M. Ramesh, and C. Deepa, "Fabrication and property evaluation of banana-hemp-glass fiber reinforced composites," Procedia Engineering, vol. 97, pp. 2032-2041, 2014.

[15] M. Ramesh, R. Logesh, M. Manikandan, N. S. Kumar, and D. V. Pratap, "Mechanical and water intake properties of banana-carbon hybrid fiber reinforced polymer composites," Materials Research, vol. 20, no. 2, pp. 365-376, 2017.

[16] M. K. B. Bakri, E. Jayamani, and S. Hamdan, "Processing and characterization of banana fiber/epoxy composites: effect of alkaline treatment," Materials Today: Proceedings, vol. 4, no. 2, pp. 2871-2878, 2017.

[17] G. Kirubakaran, M. Aadithya, C. Madankumar, and C. Senthamaraikannan, "Effect of alkaline treatment on banana fiber reinforced epoxide composites," Think India Journal, vol. 22, no. 4, 2019.

[18] T. Deac, L. Fechete-Tutunaru, and F. Gaspar, "Environmental impact of sawdust briquettes use - experimental approach," Energy procedia, vol. 85, pp. 178-183, 2015.

[19] Č. Mizera, D. Herák, M. Müller, and P. Hrabě, "Mechanical behaviour of polymeric composite with fibres of false banana (Ensete ventricosum)," Agronomy Research, vol. 13, no. 3, pp. 680-689, 2015.

[20] C. Ataguba, "Properties of ceiling boards produced from a composite of waste paper and rice husk," International Journal of Advanced Science, Engineering and Technology, vol. 2, pp. 117-121, 2016.

[21] K. Thangamani and P. Somasundaram, "Design and development of natural composite board using banana, bagasse and sisal fibre," International Journal of Innovative Research in Technology, vol. 1, no. 10, 2014.

[22] H. Jaya, N. Z. Noriman, H. K. AbdulKadir et al., "The effects of wood sawdust loading on tensile and physical properties of up/pf/wsd composites," in IOP Conference Series: Materials Science and Engineering, 2018.

[23] Y. Isheni, B. S. Yahaya, M. A. Mbishida, F. Achema, and S. KarfeGayus, "Production of agro waste composite ceiling 
board (a case study of the mechanical properties)," Journal of Scientific and Engineering Research, vol. 4, no. 6, 2017.

[24] M. T. Shedge, C. H. Patel, S. K. Tadkod, and G. D. Murthy, "Polyvinyl acetate resin as a binder effecting mechanical and combustionproperties of combustible cartridge case formulations," Defence Science Journal, vol. 58, no. 3, pp. 390-397, 2008.

[25] D. Gon, K. Das, P. Paul, and S. Maity, "Jute composites as wood substitute," International Journal of Textile Science, vol. 1, no. 6, pp. 84-93, 2012.

[26] ASTM Standard D1037, Standard Test Methods for Evaluating Properties of Wood-Base Fiber and Particle Panel Materials, ASTM International, West Conshohocken, PA, 2020.

[27] E. E. Ndububa, D. C. Nwobodo, and I. M. Okeh, "Mechanical strength of particleboard produced from Fonio Husk with gum Arabic resin adhesive as binder," International Journal of Engineering Research and Applications, vol. 5, no. 4, 2015.

[28] ASTM standrad D790, Standard Test Methods for Flexural Properties of Unreinforced and Reinforced Plastics and Electrical Insulating Materials, ASTM International, West Conshohocken, PA, 2017.

[29] A. I. Al-Mosawi, M. A. Rijab, N. Abdullah, and S. Mahdi, "Flexural strength of fiber reinforced composite," International Journal of Enhanced Research in Science Technology and Engineering, vol. 2, no. 1, pp. 1-3, 2013.

[30] ASTM standrad D570, Standard Test Method for Water Absorption of Plastics, ASTM International, West Conshohocken, PA, 2018.

[31] P. Singh and B. Singh, "Assessment of mechanical properties of biocomposite material by using sawdust and rice husk," INCAS Bulletin, vol. 11, no. 3, pp. 147-156, 2019.

[32] N. Sombatsompop, K. Chaochanchaikul, C. Phromchirasuk, and S. Thongsang, "Effect of wood sawdust content on rheological and structural changes, and thermo-mechanical properties of PVC/sawdust composites," Polymer International, vol. 52, no. 12, pp. 1847-1855, 2003.

[33] H. R. Radha, P. V. Krupakara, V. Latha, R. Lakshmi, and K. Vinutha, "Study on mechanical behavior of banana fiber reinforced epoxy composites," Asian Journal of Multidisciplinary Research, vol. 5, no. 1, p. 13, 2019.

[34] G. Goud and R. Rao, "Effect of fibre content and alkali treatment on mechanical properties of Roystonea regia-reinforced epoxy partially biodegradable composites," Bulletin of Materials Science, vol. 34, no. 7, pp. 1575-1581, 2011.

[35] A. Gopinath, M. S. Kumar, and A. Elayaperumal, "Experimental investigations on mechanical properties of jute fiber reinforced composites with polyester and epoxy resin matrices," Procedia Engineering, vol. 97, pp. 2052-2063, 2014.

[36] R. Girimurugan, K. G. Saravanan, P. Manickavasagam, G. Gurunathan, and M. Vairavel, "Experimental studies on water absorption behaviour of treated and untreated hybrid bio-composites," in IOP Conference Series: Materials Science and EngineeringIOP Publishing.

[37] T. Srinivasan, G. Suresh, P. Ramu, V. Gokul Ram, M. Giresh, and K. Arjun, Effect of Water Absorption of the Mechanical Behavior of Banana Fiber Reinforced IPN Natural Composites, Materials Today: Proceedings, 2020.

[38] M. Z. R. Khan, S. K. Srivastava, and M. Gupta, "A state-of-the-art review on particulate wood polymer composites: processing, properties and applications," Polymer Testing, vol. 89, p. 106721, 2020.

[39] P. Sahu and M. Gupta, "Water absorption behavior of cellulosic fibres polymer composites: a review on its effects and remedies," Journal of Industrial Textiles, 2020. 